\title{
Influence of Reproductive Health Unit of Instruction on Undergraduate Students' Sexuality in South-South Nigeria
}

\author{
Ihejiamaizu Christiana Chinyere ${ }^{1}$, Ajake Uchenna Egodi ${ }^{2}$, Amalu Melvina. $\mathbf{N}^{3}$, Ann Ndidi Meremikwu ${ }^{1, *}$ \\ ${ }^{1}$ Department of Curriculum \& Teaching, University of Calabar, Calabar, Nigeria \\ ${ }^{2}$ Institute of Education, University of Calabar, Calabar, Nigeria \\ ${ }^{3}$ Department of Educational Foundation, Guidance \& counseling, University of Calabar, Calabar, Nigeria \\ *Corresponding author: annemeremikwu@yahoo.com
}

Received May 03, 2013; Revised June 27, 2013; Accepted June 28, 2013

\begin{abstract}
This study investigated the influence of Reproductive Health Unit of Instruction (RHUI) on undergraduate students' sexuality in south-south Geopolitical zone of Nigeria. Quasi-experimental research design involving pretest-post-test of experimental and control groups was used for the study. A total 400 subjects formed the sample of the study. A well validated instrument-Undergraduate Students' Sexuality Questionnaire (USSQ) was used to collect data. Treatment with the use of RHUI was given to the experimental group for one semester while the control group followed the normal existing curriculum. Analysis of Covariance Statistics (ANCOVA) was used to analyse the data collected. The result showed that the RHUI significantly improved undergraduate students' sexuality. Based on the findings, conclusions were drawn and recommendations for inclusion of RHUI in year one undergraduate students' curriculum with modification in the programming and implementation of the curriculum in response to broader needs of young people were made.
\end{abstract}

Keywords: reproductive health, unit of instruction, undergraduate, students sexuality

\section{Introduction}

It is globally acknowledged that a high proportion of young people are engaged in sexual activities. Studies from most parts of Nigeria such as [2,3,13,14,17,18] provide evidence that the incidence is on the increase. Generations ago in the Nigerian society, open discussion of sex especially among young unmarried persons was almost unheard of and infact a taboo. Traditional norms then controlled young people's sexuality. Today, the story has changed dramatically, due to the erosion of the traditional norms. Most young people now have control over their own lives and the opportunity to make more independent decisions about their sexuality. Hence, they engage in open and more liberal sexual activities through the dating system of boyfriend and girlfriend [13].

Research attributes the erosion of traditional norms that used to shape young people's sexual behavior to modernity and western culture that are permissive of sensationalized romantic love most times in mass media [13]. More so, traditional culture and exigencies made for early marriages. A girl for example was meant to marry just upon attaining adolescence. Thus able to have sexual gratification early without breaking cultural norms. Today transition is delayed by education. This delay does not correspondingly delay the desire for sexual gratification. These effects according to Ikoroku have left young people ignorant, gullible and susceptible to wrong conducts with respect to their sexuality. As a result, young people now discover their own world of sex and as such, most of them become sexually active with little or no knowledge about sexual issues and facts. Such a pattern of sexual activity puts young people to more sexual and reproductive health risks.

Examples of this risk include; unwanted pregnancies and their complications, sexually transmitted diseases (STDs), illegal abortions and school dropout among others. Where the pregnancies are carried out to full term for the very young, [15] notes that there may be sustained obstetric complications due to the young people's immature bodies. Even where the babies are delivered, [12] reports increased abandonment of babies in squalid places. Thus the evidence is convincing that the most young people who are sexually active lack sufficient knowledge of human sexuality which reflects in their illicit sexual behaviour with negative attitude to the corresponding health services. This scenario suggests urgent need for educational intervention and greater motivation for health enhancing behaviour.

The trend of sexual behaviour among young people has been of great concern to researchers, educators, programme developers and policy makers in government and other social organizations in the country. These concerned groups have implemented intervention programmes through media with jingles such as "Say No to Aid", Zip up-sex is worth waiting for ". Others have organized seminars, voluntary counseling and testing (VCT) and sex education has long been implemented in 
schools as initiatives to curb the problem. These efforts do not appear to have made much impact.

[3] opined that due to the existing conservative attitude towards sexual issues in the society, sex and sex-related issues are either superficially discussed or completely neglected. He contends that what are taught in sex education in Nigerian schools never go beyond the basics and therefore lack sufficient details to allow young people particularly deal with issues that confront them. In addition, he noted that most programme implementers are often concerned about the potential of the programmes, inadvertently condoning young people's early sexual activity. Although that may be the case, the little impact made by the existing programmes suggests that a more encompassing curriculum in sexual, reproduction and family planning issues that vary widely in its aims, scope and content need to be implemented. However, no systematic investigation has been conducted in the southsouth zone of Nigeria to establish the effect of such programmes, not even at the tertiary educational level. The need to feel this gap is what has motivated the undertaking of the present research. The research was aimed at determining the influence of reproductive health instruction on undergraduate students' sexuality in the south-south geopolitical zone of Nigeria.

\section{Literature Review}

The relevance of using education as a tool in checking increased sexual activity has been globally reported among young people. The tendency of the present day young person engaging in intense and uninformed pattern of sexual activity is explained on the frame work of Sigmund Freuds psychoanalytic theory. $[9,10]$ conceive man as a bundle of sexual energy with intense drive in adolescence. The theorist further believed that development of appropriate sexual behaviour in man can only be achieved through early and appropriate home and school training on sexual issues as this could help a child to adjust and learn mature and more informed sexual behaviours. The expression of sexual tendency is inherent in the life of people. People reach sexual maturity and tend to initiate sexual activity before they develop mental and emotional maturity needed to appreciate the consequences of their sexual activity. Thus, without access to sexuality information, the young people tend to experiment with risk sexual practices, with the consequence on their sexual and reproductive health (16; 8). Supporting this view, 5) provided rationale for and evidence of positive outcome of sexuality education.

To [14] the aftermath of sexual permissiveness such as sexually transmitted infection (STIs), pregnancy and school drop-out could be checked through well packed sexuality instruction. Similarly, the World Health Organization [23] demonstrates that the present status of reproductive health of young people in Nigeria could be addressed through National Invention Programmes.

Expressing obvious support for sex education, [6] argues that cultural practices which inhibit open discussion of sexuality in Nigeria society leave young people to discover their own sex world without being aware of the inherent dangers of their practices. By implication, a child is better off with sexuality education.
Expressing concern over the overbearing influence of the cultural conservatives due to virtual absence of sexuality education [3] laments that most Nigerian young people receive sexual information from various sources including peers, sibling, school mates, print and electronic media. Such sources of sexual information noted are associated with trial and error learning and risky sexual experimentation.

A study in Calabar, Nigeria by [19] using 166 respondents found that $91 \%$ knew that a girl can become pregnant when she begins to menstruate. Majority of the respondents (96\%) did not know that sex, even once could result in pregnancy. The result of this study further shows that adolescents though may be knowledgeable about onset of puberty, have poor knowledge about reproductive physiology and hence poor knowledge about pregnancy.

The authors also explained that since some adolescents may not be involved in regular sex, it is possible that they may not therefore anticipate that every sexual act could lead to pregnancy. Complimenting this view, [21] stresses that young people need sufficient knowledge of the anatomy and physiology of the masculine and feminine genitalia. [21] maintains that such instruction would give idea about what young people will experience in their own bodies with maturity. Conversely the author cautions that if young people lack knowledge about sexual issues, the ignorance may lead to sexual misadventure with undesirable consequences. Corroborating [21] view, [16] urged that the fundamentals of human sexuality and reproduction should be taught to young people. She explained that such exposure would equip and allow them to become familiar with the mystery of life and the risks involved in sexual act. [16] concludes that with adequate background knowledge, young people may adopt responsible attitude toward sexual matters .

\section{Material and Method}

Participants: Two hundred (200) participants in the experimental group and two hundred (200) participants in the control group making up a total of four hundred (400) participants formed the sample of the study. A breakdown of the two hundred participants in the experimental group gave one hundred (100) males and one hundred (100) females. (The same number also constituted male and female.) The same number also constituted male and female categories in the control group.

Instrumentation: Well validated instrument captioned Undergraduate Students' Sexuality Questionnaire (USSQ) was used for data gathering. The research instrument comprises three sections. Section 'A' deals with the' personal data. It contains 5-items viz: University, faculty, form number, sex and age. Section 'B' contains 10-items measuring students'sexuality activity. This was arranged in four point likert type, scale ranging from Strongly Agree (SA), Agree (A), Disagree (D) and Strongly Disagree (SD). Section ' $C$ ' is a 14-items likert scale type measuring students' reproductive health knowledge arranged also in four point scale. Respondents were to tick the options that explain their sexual activity and knowledge. A total of 400 copies of the questionnaire were distributed, retrieved and used for the study. 


\section{Research Methodology}

The study covered all year one undergraduate students' in the public Universities in south-south geopolitical zone of Nigeria. A pretest and Post-test was administered with the control group. Quasi-experimental design was used for the study. Out of seven (7) existing public universities in the area, two (2) were randomly selected and were also assigned as experimental and control groups respectively to avoid interactions among them. Ten (10) faculties were randomly selected across the two universities. These constitute the intact classes exposed to treatment where forty (40) participants per class were used for the study. However, assignment of the participants to either experimental or control group was not by randomization since intact classes were used.Intact classes of the experimental group were treated with the Reproductive Health Unit of Instruction which was incorporated into GSS IIII for one semester. Intact classes of the control group followed the normal existing curriculum for GSS IIII. RHUI topics covered include: human sexuality, anatomy and physiology of human reproductive system, puberty, ovulation/menstruation, masturbation, adolescence and sex drive in young boys and girls, adolescent pregnancy, abortions, sexuality transmitted infections including HIV/AIDs, abstinence, contraceptive and their operations and benefits. Two hundred (200)participants in the experimental group and two hundred (200) participants in the control group constituted the sample of the study.

\section{Results and Discussion}

Using the analysis of covariance with pre-test scores as covariates the hypothesis that says that there is no significant difference between the influence of reproductive health education and normal curriculum on undergraduate students' sexuality was tested as shown in Table 1.

Hypothesis: There is no significant difference between the effect of reproductive health education and normal curriculum on undergraduate students' sexuality in southsouth Nigeria. Analysis of covariance with pre-total reproductive health education as covariate. The result is presented in Table 1:

Table 1. Summary of analysis of covariance (ANCOVA) of the students post-total reproductive health education of the treatment with pre-total reproductive health education as covariate

\begin{tabular}{|c|c|c|c|c|c|}
\hline Treatment & $\mathrm{N}$ & & $\mathrm{X}$ & \multicolumn{2}{|c|}{ SD } \\
\hline Experimental & 200 & & 74.48 & \multicolumn{2}{|c|}{5.33} \\
\hline Control & 200 & & 73.03 & \multicolumn{2}{|c|}{5.09} \\
\hline Total & 400 & & 73.76 & \multicolumn{2}{|c|}{5.25} \\
\hline $\begin{array}{l}\text { Source of } \\
\text { variation }\end{array}$ & SS & Df & $\begin{array}{l}\text { Mean } \\
\text { square }\end{array}$ & F-cal & $\begin{array}{c}\text { sig } \\
\text { level }\end{array}$ \\
\hline Model & 1521.864 & 2 & 27.823 & 31.812 & $.000^{*}$ \\
\hline Covariate & 5742.201 & 1 & 5742.201 & 240.661 & $.000 *$ \\
\hline Intercept & 1311.614 & 1 & 1311.614 & 54.8341 & $.000^{*}$ \\
\hline Treatment & 94.615 & 1 & 94.615 & 3.956 & .047 \\
\hline $\begin{array}{c}\text { Error } \\
\text { (residual) }\end{array}$ & 9496.126 & 397 & 23.920 & & \\
\hline Total & 11017.990 & 399 & & & \\
\hline
\end{tabular}

$* \mathrm{p}<.05$ alpha level

The result in Table 1 shows the summary of the analysis of covariance on the post-total reproductive health education of the student in the experimental and control groups. The experimental group was taught with the package (reproductive health education); while the control group was not. The post-total reproductive health education mean scores obtained were 74.348 and 73.03 for experimental and control groups respectively.

The result shows that the F-ratio $(\mathrm{F}=3.956, \mathrm{P}<.05)$ for post-total reproductive health education was higher than the critical value of 3.00 at .05 level of significance with 1 and 397 degrees of freedom. With this result the null hypothesis was rejected.

The result showed that the experimental group students performed significantly better in sexuality test than those in the control group. The high significant difference between the two groups is obviously due to the treatment effect. This shows that the reproductive health unit of instructions significantly improve undergraduate student sexuality. The result is in consonance with Sigmund Freuds psychoanalytic theory as applied to human sexuality which views man as a bundle of sex energy, with intense drive at adolescence and postulates that development of appropriate sexual behaviors can only be achieved through social interactions, internalization of proper instructions, societal values and standards.

This research work was supported by $[5,14,16]$ who asserted that sexuality education(especially when it is holistic)is a useful strategy and intervention for moderating the increase in the present day young people's sexual expression.

The result is in contrast to the report [22] which showed that many policy makers, public opinion leaders, religious leaders, religious groups, parents and significant others still believe that withholding information about sexual and reproductive health issues from young people will encourage them to be becoming sexually active.

Giving the increase in reckless sexual experimentation among the contemporary young people thus exposing them to greater attendant risk, it becomes imperative to consciously expose them to a corresponding early and encompassing sexual and reproductive health information. This is crucial particularly for the sexually active child to adjust to a more appropriate and informed sexual behaviour.

\section{Conclusion}

Based on the findings from the study, one could conclude that reproductive health unit of instruction significantly influenced undergraduate students sexuality with respect to sexual activity and reproductive knowledge. It was also concluded that undergraduate students who are exposed to reproductive health instruction are less likely to engage in risky and uninformed sexual practices than those who are not exposed. Therefore, a comprehensive reproductive health unit of instruction having been found very effective in this research for addressing undergraduate students sexual behaviour should be included in the tertiary school first year GSS curriculum by the educational planners and policy makers.

\section{References}


[1] Adewole, I. F., Adeniran, B. A., Oladokun, A., Gbedegesin, A. \& Babarinsa, I. A. (2002). Contraceptive usage among abortion seekers in Nigeria. West African Journal of Medicine 21(2): 112114.

[2] Adebusoye-Makinwa, P. k. (1999). Adolescent reproductive behaviour in urban Nigeria. Ibadan: Adetunji Press.

[3] Adedimeji, A. A. (2005). Beyond knowledge and behavior change. The social structural context of HIV/AIDs risk perceptions and protective behavior among young urban slum inhabitants in Nigeria. Harvard school of Public Health: Boston. U.S.A.

[4] Ajayi, V. (1980). A text book of Midwifery: Nursing and health science series. London: Macmillan Press Limited.

[5] Ajuwon, A. O. (2000). Effect of educational intervention on reproductive health knowledge, attitude and practices among secondary school students in Oyo State. Nigeria Ph.D thesis of the University of Ibadan, Nigeria.

[6] Baruch, S. E. (2002). Working with young people: Toward an agenda for sexual health. Sex and relationship therapy 15(3): 283296.

[7] Decey, J. S., \& Kenny, M. (2001). Adolescent development. Madison, Wisconsin: WCB Brown \& Benchmark.

[8] Fee, O. \& Yousef, S. (1993). Vaginal fistula in Nigerian children. The Llancet, 20(3)291-295.

[9] Freud, S. (1905). Three essays on the theory of sexuality. London: Hogarth Press.

[10] Freud, S. (1933). New introductory lectures on psycho-analysis. New York, Norton.

[11] Ihejiamaizu, E. C., \& Etuk, S. J. (2004). Induced abortion among secondary school girls in Calabar. The Nigerian Postgraduate Medical Journal, 11(4); 269-273.
[12] Ihejiamaizu, E. C. (2002). Issues in Population policy and Health Care Administration. African Scholar's publishing Company, Owerri.

[13] Ikorok, M. M. (2004). Value-based sexuality education in Nigerian schools. Nigerian Journal of Health Education (NJHE) 12(1): 37-45.

[14] Madunagu, B. E. (2000). Adolescents and problems. Girls Power Initiative (GPI), Nigeria. 2(1): 5-8.

[15] Meekers, A. (2004). Contemporary patterns of adolescent sexuality in urban Botswana. Medline Journal. 15(4): 165-171.

[16] Melgosa, J. (2001). New life style to adolescents and parents. New York: International University Press.

[17] Otoide, V. A., Oronsaye, F. \& Okonofua, F. E. (2001). Why Nigerian adolescents use induced abortion rather than contraceptive. International Family Planning Perspectives, 27(2), 77-81.

[18] Okonofua, F. E. (1992). Preventing unsafe abortion in Nigeria. African Journal of Reproductive Health. 1(1): 25-36.

[19] Oyo-Ita, A. E., Kalu, N., Mkpanam, N. E., Ikpeme, B. O., \& Etuk, S. J. (2002). Knowledge of reproductive health issues among secondary school adolescents in Calabar. African Journal of Medical Science. 2(1): 4-12.

[20] Population Reference Bureau (2002). Meeting young women's reproductive sexual health needs. (Publication of women's health action research, USA)

[21] Tieno, A. S. (1992). Off our backs: Sexuality and popular culture. New York: Gale Group.

[22] World Health Organization (1998). Report on global HIV/Aids epidemic. Adolescent Health and Development Programme. 1: 4-8.

[23] World Health Organization (1999). Global programmes on Aids. London: Prentice Hall. 